\title{
DISPONIBILIDADE DE COBRE E ZINCO EM SOLOS TROPICAIS AVALIADA PELO PROCESSO DE EXTRAÇÃO SEQUENCIAL (BCR)
}

\author{
Lucília Alves Linhares $^{1 *}$, Fernando B. Egreja Filho ${ }^{1}$, Vito Modesto de Bellis ${ }^{1}$, Elisângela A. dos Santos ${ }^{1}$ \\ ${ }^{1}$ Universidade Federal de Minas Gerais, Instituto de Ciências Exatas, Departamento de Química, Avenida Antônio Carlos, $n^{\circ}$ 6627, \\ CEP 31270-901, Belo Horizonte, MG. \\ *Email: lalinhares@hotmail.com
}

\begin{abstract}
RESUMO
Em estudos ambientais, conhecer as formas químicas em que se encontram os elementos no solo e suas relações com os teores disponíveis são importantes para a previsão do comportamento no sistema solo-planta. Para avaliar a distribuição de cobre e de zinco em solos do Estado de Minas Gerais e sua relação com a disponibilidade, realizou-se o experimento com amostras de seis solos naturais em duas profundidades, as quais foram contaminadas com os elementos de interesse e submetidas ao processo de extração seqüencial que separa os elementos nas frações trocável, oxidável, redutível e residual. O fracionamento forneceu importantes informações em relação à interação do cobre e do zinco com os constituintes dos solos e da compartimentação dessas espécies entre as várias frações dos solos. Verificou-se uma maior distribuição de zinco nas frações trocável e residual, enquanto que o cobre se associou preferencialmente às formas químicas mais estáveis, ou seja, redutível e residual. As baixas recuperações de zinco e principalmente de cobre na fração trocável no Chernossolo Argilúvico Carbonático (solo 2) e no Cambissolo Háplico eutrófico latossólico (solo 3) corresponde a sistemas solo-metal com as maiores forças de retenção, estando os elementos nesses solos menos disponíveis. A predominância de cobre e principalmente de zinco associados à fração trocável no Cambissolo Háplico Tb distrófico típico (solo 4) e no Neossolo Quartzarênico órtico latossólico (solo 6) evidencia a maior mobilidade e disponibilidade dos metais nos solos mais ácidos e arenosos comparado com os demais.
\end{abstract}

Palavras-chave: Distribuição. Metais Pesados. Fracionamento. Extração.

\section{Introdução}

Íons metálicos como $\mathrm{Cu}^{2+}$ e $\mathrm{Zn}^{2+}$ considerados como elementos essenciais na nutrição mineral, bioquímica e fisiológica das plantas, quando presentes em altas concentrações no solo podem apresentar caráter tóxico, causando problemas no metabolismo dos seres vivos [1]. A mobilidade de elementos no perfil do solo é uma das grandes preocupações, no que diz respeito ao potencial poluente. Embora o solo atue como uma barreira de proteção natural, os fatores que governam sua capacidade em reter diferentes elementos são bastante complexos, o que dificulta sobremaneira o seu entendimento e as possibilidades de previsões acerca do comportamento desses elementos, principalmente a longo prazo [2].

Dentre os processos envolvidos no comportamento e disponibilidade de elementos nos solos, aqueles relacionados com a distribuição são de grande importância [3,5]. Essa distribuição está intimamente associada a fatores que contribuem para a retenção do metal na fase sólida, podendo-se destacar as características de cada metal, bem como fatores do meio como: pH, textura, composição das argilas, matéria orgânica, capacidade de troca catiônica, dentre outros.

$\mathrm{Na}$ avaliação da disponibilidade de metais em solos, embora a determinação da concentração total de elementos forneça alguma indicação do nível de contaminação, esta não provê informação sobre a mobilidade e disponibilidade. Tais informações são obtidas a partir da determinação das formas químicas nas quais esses elementos se encontram associados [6], sendo determinada pela distribuição entre as várias fases do solo [7] pelo tratamento com extratores de diferentes propriedades químicas, de forma a determinar a proporção de metal associada a cada componente da fase sólida.

$\mathrm{Na}$ literatura vários trabalhos envolvendo a distribuição de metais em solos utilizando-se os métodos de extração seqüencial $[3-4,8,10]$ podem ser encontrados, porém os resultados obtidos são algumas vezes conflitantes em razão da grande variação nas metodologias propostas, às diferentes características dos solos e da própria complexidade do sistema, bem como a problemas 
como falta de seletividade, readsorção e o longo tempo necessário para realização do procedimento. No entanto, os processos de extração sequencial têm sido amplamente adotados e adaptados para várias matrizes em diferentes estudos ambientais. Um protocolo de extração que atualmente está sendo muito utilizado foi proposto por "European Communities Bureau of Reference" (BCR), baseado no procedimento de Salomons e Forstner, para programas de comparação interlaboratorial realizados na Europa [11]. É um método utilizado para determinação de inúmeros metais incluindo cobre e zinco e que será aplicado neste trabalho.

Desse modo, o presente trabalho tem por objetivo investigar a distribuição de cobre e zinco empregando-se o processo de extração sequencial e avaliar a influência das características dos solos sobre as frações obtidas, a fim de que os fatores que influem em sua distribuição possam ser determinados. $O$ trabalho envolve $\mathrm{o}$ estudo da camada superficial e subsuperficial de seis diferentes solos do Estado de Minas Gerais selecionados de forma a compor um grupo de solos que representem a região. As informações assim obtidas poderão contribuir na geração de informações relevantes para o monitoramento de solos do Estado de Minas Gerais e fornecer orientações sobre quais tipos de solos apresentam maiores ou menores problemas, quando impactados por elementos como cobre e zinco.

\section{Parte Experimental}

\subsection{Amostragem e caracterização dos solos}

O experimento foi conduzido no Laboratório de Química Ambiental da Universidade Federal de Minas Gerais, trabalhando-se com amostras da camada superficial e subsuperficial de seis solos coletadas em diferentes municípios do Estado de Minas Gerais (Tabela 1). As amostras de solos foram secas ao ar (Terra Fina Seca ao Ar), destorroadas, homogeneizadas, passadas em peneira com malha de $2 \mathrm{~mm}$ de abertura e utilizadas para caracterização química e física. Todos os reagentes utilizados no trabalho foram de grau analítico e todas as análises foram efetuadas em triplicatas.

$\mathrm{Na}$ Tabela 2 sumarizam-se os principais atributos químicos e físicos dos solos estudados. As análises de $\mathrm{pH}$ (em água e em $\mathrm{KCl}), \Delta \mathrm{pH}$, granulometria e capacidade de troca catiônica (CTC) foram realizadas conforme Embrapa [12]. Para determinação dos teores de carbono orgânico utilizou-se o método de Walkley-Black de acordo com Jackson [13]. Os teores de ferro e alumínio cristalinos e de ferro e alumínio amorfos foram extraídos com soluções de ditionito-citrato-bicarbonato (DCB) e de oxalato ácido de amônio, de acordo com [1415], respectivamente. Para a determinação dos elementos utilizou-se o espectrômetro de absorção atômica marca Perkin Elmer, modelo Analyst 200, por aspiração direta das soluções aquosas em chama ar-acetileno.
Tabela 1. Identificação, classificação, localização e profundidade dos solos estudados

\begin{tabular}{ccccc}
\hline Solo & Classificação & Município & $\begin{array}{c}\text { Prof. } \\
(\mathrm{cm})\end{array}$ \\
\hline 1 & A & Latossolo Vermelho-Amarelo Distrófico típico & Ponte Nova & $0-20$ \\
& B & & $20-200$ \\
2 & A & Italva & $0-42$ \\
& B & Chernossolo Argilúvico Carbonático & & $42-200$ \\
3 & A & & Pedro & $0-38$ \\
& B & Cambissolo Háplico eutrófico latossólico & Leopoldo & $38-200$ \\
4 & A & & & $0-20$ \\
& B & Cambissolo Háplico Tb distrófico típico & Mariana & $20-110$ \\
5 & A & Plintossolo Pétrico concrecionário distrófico & Brasilândia & $0-20$ \\
& B & & $20-50$ \\
6 & A & & Joõo Pinheiro & $0-20$ \\
& B & Neossolo Quartzarênico órtico latossólico & Joan \\
\hline
\end{tabular}

Tabela 2. Características químicas e físicas dos solos

\begin{tabular}{|c|c|c|c|c|c|c|c|c|c|}
\hline \multirow{2}{*}{\multicolumn{2}{|c|}{ Solo }} & $\mathrm{pH}^{(1)}$ & $\mathrm{CTC}^{(2)}$ & $\mathrm{COT}^{(3)}$ & Argila & $\mathrm{Fed}^{(4)}$ & $\mathrm{Feo}^{*}$ & $\mathrm{Ald}^{(5)}$ & $\mathrm{Alo}^{*+1}$ \\
\hline & & & $\mathrm{cmol}_{\mathrm{c}} \mathrm{kg}^{-1}$ & ............... & ……......... &.. $\mathrm{g} \mathrm{kg}^{-1}$ & .......... & …......... & .... \\
\hline \multirow[t]{2}{*}{1} & A & 5,50 & 10,95 & 18,83 & 604,6 & 67,25 & 1,40 & 9,54 & 2,69 \\
\hline & B & 5,27 & 5,18 & 13,28 & 659,1 & 83,60 & 0,44 & 15,95 & 1,63 \\
\hline \multirow[t]{2}{*}{2} & A & 7,16 & 23,69 & 16,55 & 494,8 & 35,79 & 4,39 & 3,30 & 3,23 \\
\hline & B & 7,46 & 28,17 & 9,06 & 486,4 & 48,40 & 4,48 & 6,42 & 2,51 \\
\hline \multirow[t]{2}{*}{3} & A & 7,52 & 12,19 & 25,26 & 524,4 & 68,62 & 1,73 & 13,43 & 13,11 \\
\hline & B & 6,91 & 5,52 & 7,83 & 703,5 & 64,09 & 1,08 & 10,11 & 2,49 \\
\hline \multirow[t]{2}{*}{4} & A & 4,93 & 2,62 & 15,33 & 190,0 & 12,53 & 1,61 & 2,77 & 3,09 \\
\hline & B & 5,20 & 1,58 & 5,65 & 185,2 & 5,56 & 1,62 & 5,07 & 2,72 \\
\hline \multirow[t]{2}{*}{5} & A & 5,61 & 3,36 & 13,12 & 147,1 & 18,10 & 1,04 & 3,65 & 0,89 \\
\hline & B & 4,30 & 2,32 & 9,46 & 193,2 & 24,65 & 0,36 & 0,00 & 0,73 \\
\hline \multirow[t]{2}{*}{6} & A & 4,49 & 1,30 & 9,07 & 110,1 & 2,73 & 0,20 & 0,92 & 0,73 \\
\hline & B & 4,71 & 1,12 & 5,06 & 148,5 & 2,17 & 0,18 & 0,71 & 0,48 \\
\hline
\end{tabular}

\subsection{Contaminação dos solos com os metais de interesse}

Os solos foram contaminados com $125 \mu \mathrm{g} \mathrm{g}^{-1}$ e $250 \mu \mathrm{g} \mathrm{g}^{-1}$ de cobre na forma $\mathrm{Cu}\left(\mathrm{NO}_{3}\right)_{2}$ e com $50 \mu \mathrm{g} \mathrm{g}^{-1}$ e $100 \mu \mathrm{g} \mathrm{g}^{-1} \mathrm{de}$ zinco na forma $\mathrm{ZnCl}_{2} \cdot 6 \mathrm{H}_{2} \mathrm{O}$ nos horizontes $\mathrm{A} e \mathrm{~B}$, respectivamente, sendo a concentração definida a partir dos resultados de Egreja Filho [5]. Os horizontes superficiais receberam o dobro da quantidade de metais dos horizontes subsuperficiais, dada a elevada capacidade de retenção pela matéria orgânica. A contaminação foi feita por 70 dias, a temperatura ambiente, com umidade mantida em $80 \%$ da capacidade de campo, controlada diariamente, por meio de pesagens e adição de água deionizada, quando necessário. A condição de maior umidade tem por objetivo favorecer o processo de difusão do metal nos solos. Foram contaminados 200 g de solo em potes plásticos, e as soluções contendo os metais foram preparadas no $\mathrm{pH}$ de cada solo, de modo a favorecer o máximo de adsorção, com o mínimo de precipitação dos hidróxidos e sais básicos. Após o período de contaminação, os solos foram secos ao ar, triturados e passados em peneira de $0,177 \mathrm{~mm}$ de abertura. 


\subsection{Procedimento de extração sequencial de metais}

A metodologia empregada para o fracionamento por extração sequencial, em três frações mais a fração residual, foi desenvolvida pelo "Standard, Measurements and Testing Program" - BCR e adaptada para $1 \mathrm{~g}$ de amostra.

Fração trocável (F1): extração dos metais com $20 \mathrm{~mL}$ de solução de ácido acético $0,11 \mathrm{~mol} \mathrm{~L}^{-1}$ sob agitação por 16 horas (overnight) a temperatura ambiente.

Fração redutível (F2): ao resíduo da primeira fração adicionou-se $20 \mathrm{~mL}$ de solução de cloridrato de hidroxilamina 0,1 mol L ${ }^{-1}$ acidificado a pH 2,0 com $\mathrm{HNO}_{3}$ e mantido sob agitação por 16 horas (overnight) a temperatura ambiente

Fração oxidável (F3): nesta etapa, o resíduo de $\mathrm{F} 2$ foi inicialmente mantido sob agitação por 1 hora a temperatura ambiente com $10 \mathrm{~mL} \mathrm{H}_{2} \mathrm{O}_{2} 8,8 \mathrm{~mol} \mathrm{~L}^{-1}$ e em seguida submetido a agitação pelo mesmo período de tempo a $85^{\circ} \mathrm{C}$. Após, nova alíquota de $10 \mathrm{~mL}$ de $8,8 \mathrm{~mol} \mathrm{~L}^{-1}$ foi adicionada, mantendo-se a agitação por mais 1 hora a $85^{\circ} \mathrm{C}$. Ao final, adicionou-se $20 \mathrm{~mL}$ de solução de acetato de amônio $1 \mathrm{~mol} \mathrm{~L}^{-1}$ e manteve-se sob agitação por 16 horas (overnight) a temperatura ambiente.

Fração residual (F4): os teores dos elementos na fração residual foram obtidos pela diferença entre o teor total e soma das frações anteriores. Os teores totais foram obtidos por digestão ácida em forno de microondas (Questron, modelo Qwave 3000) em tubos herméticos de teflon com uma mistura de $\mathrm{HCl} / \mathrm{HNO}_{3} / \mathrm{HF}$ e posterior eliminação do fluoreto com ácido bórico.

Em relação ao procedimento descrito, a seqüência de extrações (F1 a F3) foi realizada na mesma amostra, em tubos de centrífuga de polipropileno. Após cada extração, as amostras foram lavadas com água deionizada para remover a solução extratora anterior e limitar a readsorção do metal; todas as suspensões foram centrifugadas a $3000 \mathrm{rpm}$ (1600g) por dez minutos, filtrada em papel de filtro e os sobrenadantes recolhidos para determinação de cobre e de zinco em espectrofotômetro de absorção atômica.

\subsection{Análise estatística dos dados}

A influência das características dos solos na distribuição de cobre e de zinco foi avaliada pela análise de correlação de Pearson entre essas variáveis utilizando-se o software Statistica versão 7.0 .

\section{Resultados e Discussões}

Devido a variabilidade dos solos estudados, constituintes dos solos como $\mathrm{pH}$, teores de argila, matéria orgânica, capacidade de troca catiônica e teores de óxidos tiveram influência na distribuição de cobre e zinco, influindo em sua disponibilidade. Dentre os diferentes constituintes analisados, o pH apresenta especial importância, uma vez que este atributo mesmo que indiretamente pode influir em outras características dos solos. Considerando-se os valores médios obtidos, o $\mathrm{pH}$ natural dos solos variou de 4,49 a 7,52 e de 4,30 a 7,46 nos horizontes A e B, respectivamente, sendo classificados segundo Embrapa [12], como solos que variam de fortemente ácidos $(\mathrm{pH}$ 4,3 a 5,3) a moderadamente alcalinos ( $\mathrm{pH} 7,4$ a 8,3). Destes valores de $\mathrm{pH}$, o Plintossolo Pétrico concrecionário distrófico (solo 5B) apresenta o menor valor e o Cambissolo Háplico eutrófico latossólico (solo 3A), o maior valor. A classe textural exerce também importante influência na distribuição dos elementos, tendo os solos argilosos (solos 1, 2 e 3) maior potencial, se comparados com os de textura média (solo 5) e arenosa (solos 4 e 6), de reter elementos, entre eles o cobre e o zinco, minimizando a lixiviação para o lençol freático. Além do $\mathrm{pH}$, outras importantes características dos solos que influem na distribuição dos elementos foram determinadas e podem ser visualizadas na Tabela 2 .

Decorrido o tempo de contaminação dos solos com os metais de interesse, procedeu-se o fracionamento de cobre e de zinco segundo o esquema de extração seqüencial BCR para determinação da distribuição dos metais nas diferentes frações.

As Figuras 1 e 2 apresentam os percentuais de recuperação de cobre e de zinco obtidas após fracionamento em relação ao total extraído. Pela análise das figuras é notável como o cobre e o zinco se distribuem nas diferentes frações dos solos em proporções bastante variadas, salvo raríssimas exceções (zinco nos solos 4 e 6) onde os elementos não foram detectados.

O cobre mostrou-se menos móvel no perfil dos solos em comparação ao zinco e predominou em formas pouco disponíveis em um número considerável de amostras. A contribuição da fração de maior interesse ambiental, mais lábil (F1), não é expressiva para os solos $2 \mathrm{~A}, 2 \mathrm{~B}, 3 \mathrm{~A}$ e $3 \mathrm{~B}$, sendo a recuperação menor do que $5 \%$. As maiores quantidade extraídas do metal na fração $\mathrm{F} 1$ foram obtidos pelos solos 4A, 4B, 5A, 5B, 6A e $6 \mathrm{~B}$. Estes solos apresentam os menores valores de $\mathrm{pH}$, baixos teores de argila e de óxidos de ferro e de alumínio comparado com os demais. A baixa recuperação de cobre em frações mais disponíveis foram relatadas nos trabalhos de Pickering [16] e Das et al., [17]. Estes resultados concordam também com Sposito et al., [18], que obtiveram valores de cobre associado à fração trocável inferior a $10 \%$ do cobre total.

O cobre extraído da fração redutível $(\mathrm{F} 2)$, foi fração importante para algumas amostras, com teores máximos e mínimos recuperados nas camadas superficiais e subsuperficiais variando de 17,49 a $0,49 \%$ e de 14,32 a $3,39 \%$, respectivamente.

Segundo McBride [19], o cobre é dentre os íons metálicos um dos mais adsorvidos por óxidos de ferro. O mesmo autor comenta que apesar da alta afinidade do cobre por óxidos de alumínio, esta interação é menor do que a afinidade do metal pelos óxidos de ferro. Os solos 1, 2 e 3 com os maiores teores de óxidos de ferro cristalino (Tabela 2) foram os que apresentaram a maior 


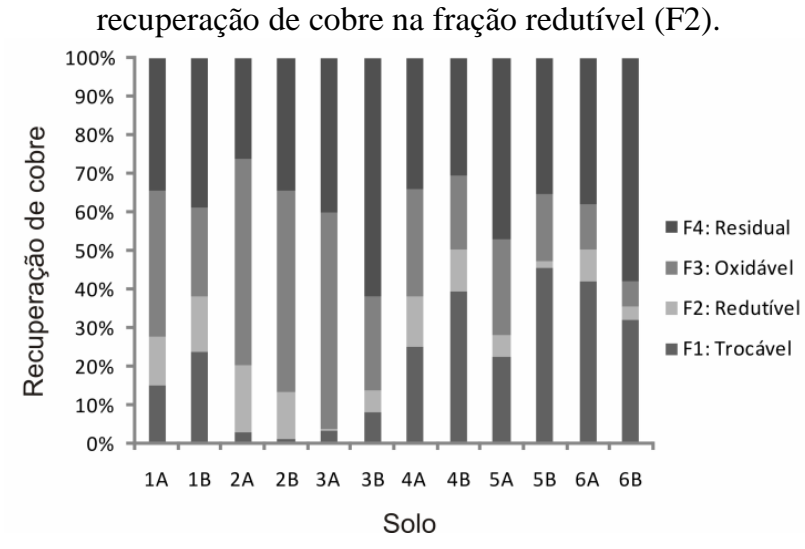

Figura 1. Percentual de recuperação de cobre nas quatro frações o procedimento de extração sequencial.

Nos solos estudados, a presença de matéria orgânica em maior quantidade no horizonte superficial explica a maior parcela de cobre extraída na fração oxidável (F3) dessas amostras. Entretanto, dos seis horizontes superficiais, os das amostras 1, 2 e 3 foram os que extraíram o metal em maiores proporções. A importância da matéria orgânica na retenção de cobre em solos tem sido relatada em diversas publicações. Neste trabalho a porcentagem máxima do metal associado a essa fração foi de $55,99 \%$. No entanto, apesar da pequena extração em algumas amostras, verificou-se correlação significativa $(0,67 *)$ entre o teor total de matéria orgânica do solo e cobre retido nessa fração. Comportamento diferenciado foi relatado por [20], que não encontraram correlação entre a matéria orgânica do solo e cobre retido na fração oxidável. Os autores observaram variação de 1,2 a 3,9 \% de cobre total associado à matéria orgânica em amostras de solo com teor de matéria orgânica entre 0,4 e 10,6\%. McBride et al., [21] relataram que a formação de complexos entre compostos orgânicos e o cobre pode aumentar a solubilidade do metal e favorecer a migração do mesmo no perfil do solo. Em estudo de 24 solos McLaren e Crawford [22] concluíram que, em média, 50\% do cobre estavam associados à fração residual, 30\% a fração orgânica e $15 \%$ aos óxidos de ferro cristalinos, sendo estas três fases a de maior estabilidade para o metal.

Além da importante complexação do cobre com substâncias orgânicas, formando complexos organo-metálicos estáveis e de baixa solubilidade, Matos et al., [23] sua imobilização pode também ser devida à ligação em frações não trocáveis do solo, o que foi comprovado por Amaral Sobrinho et al., [24] os quais verificaram em um Argissolo vermelho amarelo com baixos teores de matéria orgânica, que o cobre estava quase que totalmente ligado à fração residual e a óxidos de Fe e de Mn. Em estudo do fracionamento de cobre em nove solos contaminados [25] relataram que em média o percentual de cobre associado com as frações seguiu a ordem: residual > orgânica > óxidos de $\mathrm{Fe}-\mathrm{Mn}>$ carbonato > trocável > solúvel em água. As características de sorção de cobre em solos ácidos da Nigéria foram estudadas por [26] que relataram que o fracionamento do cobre adsorvido mostrou que entre 51 e $62 \%$ do cobre adsorvido estava na fração residual, enquanto que a forma ligada organicamente representou em média, menos do que $20 \%$ do cobre adsorvido.

Dentre as frações avaliadas, verificou-se que o cobre também foi encontrado em quantidades consideráreis na fração residual (F6), com teores extraídos variando entre $26,13 \%$ e $61,91 \%$ independentemente do horizonte. O alto índice de retenção de cobre na fração residual é indicativo de forte ligação do metal à matriz do solo. A partição de cobre e zinco em solos da Finlândia avaliada por [9] foi em média de $70 \%$ e $84 \%$ na fração residual, sendo, entretanto, esta elevada percentagem reflexo da concentração de metal nativo nos solos estudados.

A quantidade de zinco recuperada pelo fracionamento pode ser verificada na Figura 2. Assim como o cobre, o zinco apresentou-se distribuído em quase todas as frações do solo e sua distribuição também tem grande dependência do pH. Em termos percentuais, a distribuição de zinco em cada fração, em relação ao total obtido da digestão das amostras é de: 9,06 a 62,60\% na fração trocável; 0 a 20,69 \% na fração redutível; 2,86 a 35,02 \% na fração oxidável e de 5,56 a $78,26 \%$ na fração residual. É importante ressaltar que estes dados são referentes aos menores e maiores percentuais de recuperação de zinco dentre os diferentes horizontes e solos o que possibilita verificar que a distribuição desse elemento é bastante variável.

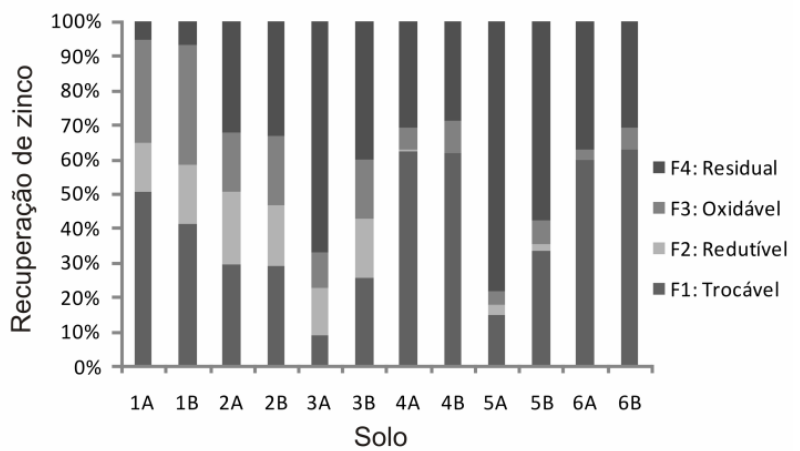

Figura 2. Percentual de recuperação de zinco nas quatro frações do procedimento de extração sequencial.

A fração trocável considerada de maior disponibilidade, onde o zinco é mais facilmente lixiviado, foi para várias amostras a fração que mais extraiu o elemento. Nesta fração o zinco pode encontrar-se dissolvido na solução do solo e/ou retido por forças eletrostáticas (adsorção não específica) nas cargas negativas das argilas, podendo ser trocado por outros íons em solução. Dentre os solos investigados, verificou-se que as amostras $2 \mathrm{~A}, 2 \mathrm{~B}, 3 \mathrm{~A}$, $3 \mathrm{~B}$ e $5 \mathrm{~A}$ foram as que menos extraíram o metal. A maior retenção de zinco em sítios mais específicos nos solos apresentados deve-se a variadas características dos mesmos, sobretudo ao maior $\mathrm{pH}$ dessas amostras bem como aos consideráveis teores de argila e de óxidos de ferro. Em contrapartida, as amostras 1A, 1B e principalmente 4A, 4B, $6 \mathrm{~A}$ e $6 \mathrm{~B}$ foram as que mais recuperaram o elemento. 
A maior parte do zinco extraído nos diferentes tratamentos seqüenciais deu-se principalmente nas frações $\mathrm{F} 1 \mathrm{e}$ F4 em um número considerável de amostras. Conforme descrito por [27], o zinco é um elemento relativamente móvel, portanto pode ser encontrado nas frações solúvel e trocável e redutível. Em ensaios de longa duração (5-20 anos) [28] relataram que o zinco encontrava-se predominantemente ligado a fração redutível, enquanto o mais recentemente adicionado (30 a 360) dias apresentava maiores teores nas formas mais reativas (solúvel e trocável).

A extração de zinco na fração oxidável foi maior no horizonte A das amostras 1, 2 e 3, com teores máximos extraídos de $17,24 \%$ e $29,23 \%$ para os solos 1 e 2 . As formas de zinco que resistiram a todas as extrações prévias foram determinadas por digestão total das amostras na fração residual. A ocorrência de zinco nesta fração do solo já poderia existir nessa forma por um processo de longa data, podendo sua ocorrência ser devido à presença de zinco herdado do material de origem, encontrado na estrutura de minerais silicatados e de óxidos de ferro e de alumínio, bem como a presença de zinco retido fortemente na superfície dos componentes da fração húmica e dos óxidos de ferro e de alumínio cristalinos. Para os solos estudados, a mínima e máxima percentagem de zinco extraído na fração residual foi de 5,56 e $78,26 \%$, sendo que destes solos, os que mais extraíram o elemento foram as amostras $3 \mathrm{~A}, 5 \mathrm{~A}$ e $5 \mathrm{~B}$.

Os resultados obtidos por [25] para fracionamento de zinco em solos contaminados mostraram que o elemento se concentrou em maiores proporções na fração residual apesar de também estar presente em outras frações. A percentagem total de zinco na fração residual variou de $55,8 \%$ a $97,6 \%$, refletindo a grande tendência do metal de se encontrar em formas não disponíveis. A percentagem de zinco presente na fração não residual foi de $2,4 \%$ a $44,20 \%$ de zinco, sendo grande parte desta percentagem obtida da fração associada aos óxidos de ferro e de manganês e parte extraída da fração trocável e ligada a carbonatos.

A susceptibilidade dos constituintes dos solos na retenção dos elementos nas diferentes frações avaliada pela análise de correlação (Tabelas 5 e 6) mostra importantes correlações entre essas variáveis. A fração considerada mais disponível (F1), onde os metais nos solos podem ser lixiviados mais facilmente, foi influenciada pelo $\mathrm{pH}$ tanto para cobre como para o zinco como mostra o coeficiente de correlação linear entre essas variáveis $(-0,93 *$ e $-0,69 *)$. A correlação negativa entre essas variáveis indica que os solos que apresentam os menores valores de $\mathrm{pH}$ (mais ácidos) apresentam os maiores valores de $\mathrm{F} 1$, ou seja, são solos que adsorvem os elementos com menoforça de retenção, sendo, portanto, mais facilmente extraídos e mais vulneráveis a contaminação.

A capacidade de troca catiônica afetou a distribuição de cobre nas frações F1 e F3 e zinco na fração F2 apresentando significativos coeficientes de correlação $\left(-0,79^{*}\right.$ e $\left.-0,87^{*}\right)$ e $\left(0,76^{*}\right)$, respectivamente. A fração argila, importante na retenção de elementos, apresentou correlação significativa e negativa com os valores de F1 para cobre $(-0,63 *)$ e correlação positiva com os valores de F2 e F3 para zinco $\left(0,81^{*}\right.$ e $\left.0,82^{*}\right)$, enquanto que os teores de areia mostraram uma relação direta com $\mathrm{F} 1$ para cobre e zinco $(0,71 *$ e $0,78 *)$. A correlação positiva entre F1 e os teores de areia é um comportamento esperado, uma vez que sendo a fração F1 considerada de maior disponibilidade, sua relação com as frações mais finas do solo deve ser favorecida, ou seja, deve ser uma relação direta.

Tabela 5. Coeficiente de correlação entre os atributos dos solos e as frações de cobre no solo

\begin{tabular}{lcccc}
\hline \multirow{2}{*}{ Atributos } & \multicolumn{4}{c}{ Cobre $^{(1)}$} \\
\cline { 2 - 5 } & $\mathrm{F} 1$ & $\mathrm{~F} 2$ & $\mathrm{~F} 3$ & $\mathrm{~F} 4$ \\
\hline pH & $-0,93^{*}$ & $0,12^{\mathrm{ns}}$ & $0,86^{*}$ & $0,01^{\mathrm{ns}}$ \\
Argila & $-0,63^{*}$ & $0,14^{\mathrm{ns}}$ & $0,44^{\mathrm{ns}}$ & $0,19^{\mathrm{ns}}$ \\
Silte & $-0,33^{\mathrm{ns}}$ & $0,37^{\mathrm{ns}}$ & $0,42^{\mathrm{ns}}$ & $0,02^{\mathrm{ns}}$ \\
Areia & $0,71^{*}$ & $-0,08^{\mathrm{ns}}$ & $-0,59^{*}$ & $-0,16^{\mathrm{ns}}$ \\
CTC & $-0,79^{*}$ & $0,43^{\mathrm{ns}}$ & $0,87^{*}$ & $-0,39^{\mathrm{ns}}$ \\
COT & $-0,55^{\mathrm{ns}}$ & $0,16^{\mathrm{ns}}$ & $0,67^{*}$ & $-0,30^{\mathrm{ns}}$ \\
Fed & $-0,64^{*}$ & $0,14^{\mathrm{ns}}$ & $0,54^{\mathrm{ns}}$ & $0,04^{\mathrm{ns}}$ \\
Feo & $-0,71^{*}$ & $0,53^{\mathrm{ns}}$ & $0,82^{*}$ & $-0,49^{\mathrm{ns}}$ \\
Ald & $-0,53^{\mathrm{ns}}$ & $0,12^{\mathrm{ns}}$ & $0,41^{\mathrm{ns}}$ & $0,08^{\mathrm{ns}}$ \\
Alo & $0,52^{\mathrm{ns}}$ & $-0,26^{\mathrm{ns}}$ & $0,66^{*}$ & $-0,12^{\mathrm{ns}}$ \\
\hline (1) Fraç̃es de & cobre no solo F1: Trocável; F2: Redutível; F3: Oxidável, F4*
\end{tabular}

(1) Frações de cobre no solo F1: Trocável; F2: Redutível; F3: Oxidável, F4: Residual; significância estatística: ns: não significativo; *significativo a $5 \%$ de probabilidade.

Tabela 6. Coeficiente de correlação entre os atributos dos solos e as frações de zinco no solo

\begin{tabular}{lcccc}
\hline \multirow{2}{*}{ Atributos } & \multicolumn{4}{c}{ Zinco $^{(1)}$} \\
\cline { 2 - 5 } & $\mathrm{F} 1$ & $\mathrm{~F} 2$ & $\mathrm{~F} 3$ & $\mathrm{~F} 4$ \\
\hline $\mathrm{pH}$ & $-0,69^{*}$ & $0,79^{*}$ & $0,31^{\mathrm{ns}}$ & $0,16^{\mathrm{ns}}$ \\
Argila & $-0,39^{\mathrm{ns}}$ & $0,81^{*}$ & $0,82^{*}$ & $-0,36^{\mathrm{ns}}$ \\
Silte & $-0,85^{*}$ & $0,14^{\mathrm{ns}}$ & $-0,20^{\mathrm{ns}}$ & $0,80^{*}$ \\
Areia & $0,78^{*}$ & $-0,75^{*}$ & $-0,58^{\mathrm{ns}}$ & $-0,12^{\mathrm{ns}}$ \\
CTC & $-0,44^{\mathrm{ns}}$ & $0,76^{*}$ & $0,42^{\mathrm{ns}}$ & $-0,11^{\mathrm{ns}}$ \\
COT & $-0,45^{\mathrm{ns}}$ & $0,30^{\mathrm{ns}}$ & $-0,01^{\mathrm{ns}}$ & $0,29^{\mathrm{ns}}$ \\
Fed & $-0,52^{\mathrm{ns}}$ & $0,84^{*}$ & $0,83^{*}$ & $-0,26^{\mathrm{ns}}$ \\
Feo & $-0,31^{\mathrm{ns}}$ & $0,59^{*}$ & $0,23^{\mathrm{ns}}$ & $-0,06^{\mathrm{ns}}$ \\
Ald & $-0,39^{\mathrm{ns}}$ & $0,66^{*}$ & $0,74^{*}$ & $-0,27^{\mathrm{ns}}$ \\
Alo & $0,48^{\mathrm{ns}}$ & $0,31^{\mathrm{ns}}$ & $0,03^{\mathrm{ns}}$ & $0,29^{\mathrm{ns}}$ \\
\hline (1) Fracões de zinco no solo F1: Trocável; F2: Redutível; F3: Oxidável, F4*
\end{tabular}

(1) Frações de zinco no solo F1: Trocável; F2: Redutível; F3: Oxidável, F4: Residual; significância estatística: ns: não significativo; *significativo a $5 \%$ de probabilidade.

É conhecida a importante relação entre os teores de matéria orgânica e as superfícies dos óxidos de ferro e de alumínio para com os elementos estudados. Para o cobre, a fração oxidável (F3) foi a que assumiu maior importância na retenção do metal $\left(0,67^{*}\right)$, sendo um dos sítios mais ativos de adsorção do elemento. No entanto, para este elemento, os óxidos de ferro e de alumínio amorfo também apresentaram correlação significativa na fração oxidável. Em relação ao zinco, além das correlações significativas de $\mathrm{F} 2$ com o $\mathrm{pH}$, com os teores de argila e com a CTC, a distribuição do metal na fração redutível foi significativa, sendo influenciada pelos óxidos de ferro e de alumínio cristalino e alumínio amorfo $(0,84 *, 0,59 *$ e $0,66 *)$. 


\section{Conclusões}

Neste trabalho, o processo de extração aplicado forneceu importantes informações em relação à interação do cobre e do zinco com as superfícies sólidas e da compartimentação dessas espécies entre as várias frações dos solos. Verificou-se que o zinco apresentou-se mais associado às frações trocável e residual e o cobre reteve-se a fração redutível e residual. A maior disponibilização de cobre nos solos $4 \mathrm{~A}, 4 \mathrm{~B}, 5 \mathrm{~B}, 6 \mathrm{~A}$ e $6 \mathrm{~B}$ e de zinco nos solos 1A, 1B, 4A, 4B, 6A e 6B indica maior disponibilidade dos solos frente à carga contaminante, o que pode ser entendido como condição favorável, à priori, a uma maior contaminação. Para condições de menor disponibilidade, os elementos nos solos 2A, 2B, 3A e 3B, principalmente para o cobre, ficaram mais adsorvidos sendo estes solos menos expostos à condição de contaminação.

\section{Agradecimentos}

Ao CNPq pela concessão da bolsa de estudo durante a execução deste projeto de pesquisa.

\section{AVAILABILITY OF COPPER AND ZINC IN SOILS EVALUATED BY SEQUENTIAL EXTRACTION PROCEDURE BCR}

ABSTRACT: In environmental studies, knowledge of the chemical forms of copper and zinc and the relationships with the levels available, are important for predicting the elements behavior in the soil-plant system. To assess the distribution of copper and zinc in soils of Minas Gerais State and their relations with their availability, an experiment was carried out on samples from six natural soils at two depths. The soil samples were incubated with the elements of interest and subjected to sequential extraction for separation of the elements in six fractions defined operationally. The results showed that the technique provided valuable information regarding the interaction of copper and zinc in soil and their speciation in various fractions of soils. There was a larger distribution of zinc in the exchangeable fraction and residual, while copper was preferably associated to more stable chemical forms, that is, related to reducible and residual forms. The nearly null extractions of copper and zinc from the soluble fraction and the exchangeable Argilúvico Chernosol (soil 2) and Tb eutrophic Haplic Cambisol (soil 3) systems correspond to the soil-metal system with the largest retention and lower availability of the elements in these soils. The predominance of copper and zinc associated mainly with the soluble and exchangeable fractions in Cambisol (soil 4) and latosol orthic Quartzarenic Neosol (soil 6) showed increased mobility and availability of the metals in more acidic and sandy soil when compared with the other soils.

\section{Referências}

[1] SUN, B.; ZHAO, F.J.; LOMBI, E. \& McGRATH, S.P. Environmental Pollution, 113:111-120, 2001.

[2] OLIVEIRA, F.C.; MATTIAZZO, M.E. Scientia Agrícola, Piracicaba, 58, 4, 807-812, 2001.

[3] TESSIER, A.; CAMPBELL, P.G.C.; BISSON, M. Analytical Chemistry, $51,844,1979$

\section{[4] SHUMAN, L.M. Soil Science, 140, 11-22, 1985.}

[5] EGREJA FILHO, F.B. Extração seqüencial de metais pesados em solos altamente intemperizados: utilização de componentes-modelo e planejamento com misturas ternárias na otimização do método. Viçosa, 2000. 287p. Tese (Doutorado em Solos e Nutrição de Plantas), Departamento de Solos e Nutrição de Plantas, UFV, Minas Gerais.

[6] SHUMAN, L.M. Chemical forms of micronutrients in soils. p.113-144, 1991. In: J.J. Mortvedt et al. Micronutients in agriculture. 2nd ed. SSSA Book Ser.4, Madison, WI.

[7] HAN, F.X.; BANIN, A.; KINGERY, W.L.; TRIPLETT, G. B.; ZHOU, L.X.; ZHENG, S.J.; DING, W.X. 8 ,113-120, 2003.

[8] GOMES, P.C.; FONTES, M.P.F.; COSTA, L.M.; MENDONÇA, E.S. Revista Brasileira de Ciência do Solo, Viçosa, 21, 543-551, 1997.

[9] KAASALAINEN, M. \& YLI-HALLA, M. 126, 225-233, 2003

[10] ABOLlinO, O.; GIACOMINO, A.; MALANDRINO, M.; MENTASTI, E.; ACETO, M.; BARBERIS, R. Water, Air and Soil Pollution, 137, 315338,2006

[11] URE, A.M.; QUEVAUVILLER, PH.; MUNTAN, H.; GRIEPINK, B. International Journal Environmental Analytical Chemistry, 51, 135-151, 1993.

[12] EMBRAPA - Empresa Brasileira de Pesquisa Agropecuária. Centro Nacional de Pesquisa de Solos. Sistema Brasileiro de Classificação de Solos. Rio de Janeiro, 412, 1999.

[13] JACKSON, M.L. Soil Chemical Analysis, Prentice-Hall, Englewood Cliffs, N.J. 1958.

[14] MEHRA, O. P., \& JACKSON, M. L. In: Clays \& Clay Mineral Conference, 7., London, 1960. Proceedings. London, 7, 317-327, 1960.

[15] MCKeAGuE, J. A., \& DAY, J. H. Canadian Journal of Soil Science, v.46, p.13-22, 1966

[16] PICKERING, W.F. CRC-Critical Reviews in Analytical Chemistry, 233-266, 1981.

[17] DAS, A. K.; CHAKRABORTY, R.; CERVERA, M.L. Guardia, M. Metal speciation in soil matrices. Talanta, 42, 1007-1030, 1995.

[18] SPOSITO, G.; BINGHAM, F.T.; YADAV, S. S.; INOUYE, C. A. Soil Science Society of America Journal, 46, 51-56, 1982.

[19] MCBRIDE, M. B. Environmental chemistry of soils, New York: Oxford University Press, 406, 1994.

[20] KUO, S.; HEILMAN, P.E.; BAKER, A.S. Soil Science, 135, 101-109 , 1983. 
[21] MCBRIDE, M.B.; RICHARDS, B.K.; STEENHUIS, T.; RUSSO, J.J. SAUVE, Soil Science, 162, 7,487-500, 1997.

[22] MCLAREN, R. G. \& CRAWFORD, D. V. Journal of Soil Science, v. 24, $172-181,1973$.

[23] MATOS, A.T.; FONTES, M.P.F.; JORDÃO, C.P.; COSTA, L.M. Revista brasileira de Ciência do Solo, 20, 379-386, 1996.

[24] AMARAL SOBRINHO, N.M.B., VELLOSO, A.C.X., OLIVEIRA, C. Revista Brasileira de Ciência do Solo, 21, 1, 9-16, 1997.

[25] MA, L.Q. \& RAO, G.N. J. Environ. Qual., 26, 259-264, 1997.

[26] AGBENIN, J.O. \& ATIN, A.M. Water, Air, and Soil Pollution, 150, 43$58,2003$.

[27] ANDRÉ, E.M.; CRUZ, M.C.P.; FERREIRA, M.E.; PALMA, L.A.S. Revista Brasileira de Ciência do Solo, Viçosa, 27, 3, 2003.

[28] NASCIMENTO, C.W.A.; FONTES, R.L.F.; NEVES, J.C.L.; MELÍCIO, A.C.F.C. Revista Brasileira de Ciência do Solo, Viçosa, 6, 3, 599-606, 2002. 